\title{
Expression of VAT1 in hepatocellular carcinoma and its clinical significance
}

\author{
Heng WANG ${ }^{1,2,3, *}$, Fei WEI ${ }^{1,2, *}$, Wanhai $\mathrm{LI}^{1}$, Qian $\mathrm{LI}^{1,3}$, Dan-Lei XIONG ${ }^{3,4}$, Ying-Yu MA ${ }^{3, *}$, Da-Hong ZHANG ${ }^{1,2, *}$ \\ ${ }^{1}$ Graduate Department, Bengbu Medical College, Bengbu, China; ${ }^{2}$ Department of Urology, Zhejiang Provincial People's Hospital, People's Hos- \\ pital of Hangzhou Medical College, Hangzhou, China; ${ }^{3}$ Clinical Research Institute, Zhejiang Provincial People's Hospital, People's Hospital of \\ Hangzhou Medical College, Hangzhou, China; ${ }^{4}$ School of Medicine, Hangzhou Normal University, Zhejiang, China
}

*Correspondence: mayingyu@hmc.edu.cn; urology@zju.edu.cn

${ }^{*}$ Contributed equally to this work.

Received August 10, 2020 / Accepted November 27, 2020

\begin{abstract}
The objective of this study was to investigate the expression of vesicular amine transporter 1 (VAT1) in hepatocellular carcinoma (HCC) and its prognostic value and to analyze the relationship between VAT1 expression and clinicopathological features of HCC. First, several public databases, including Ualcan, GEPIA, and Oncomine, were used to analyze the expression of VAT1 in HCC and normal liver tissue. Next, 330 HCC and 190 normal liver samples were stained by immunohistochemistry and scored. Finally, we evaluated the clinical significance of VAT1 as a prognostic factor according to the clinicopathological characteristics. We observed that the expression level of VAT1 in HCC samples was significantly higher than that in normal liver tissues, and the high expression of VAT1 protein in HCC was significantly correlated with patient age, tumor size, number of tumors, and vascular metastasis $(\mathrm{p}<0.05)$. The average survival time of HCC patients with high expression of VAT1 was significantly lower than that of patients with low expression of VAT1. Further analysis demonstrated that VAT1 expression was significantly correlated with the length of overall survival in HCC patients. In conclusion, VAT1 may have an essential function in the progression of HCC, and the level of its expression may effectively predict the invasion and prognosis of HCC. Moreover, the combination of information contained in public databases and the results of the analysis of clinical samples can help us to understand better the mechanism of action of molecular oncogenes in HCC.
\end{abstract}

Key words: hepatocellular carcinoma, vesicular amine transporter, VAT1, prognostic marker, bioinformatics

Hepatocellular carcinoma (HCC) is one of the most common tumors of the digestive system, and its incidence increases continuously. Recently, HCC has become the sixth most prevalent cancer $[1,2]$. Despite the improvement in the diagnosis of HCC and the development of new treatment strategies, such as surgical resection, embolization, radiotherapy, chemotherapy, ablation, and liver transplant, the prognosis and survival rate of HCC patients are poor due to the high recurrence and metastasis rates of HCC [3-5]. The reason for these unfavorable outcomes is that most of the available therapies are suitable for the early stages of HCC, while most patients are already in the middle and advanced stages of HCC at the time of diagnosis. Thus, the need for identifying new liver cancer markers and therapeutic targets is apparent.

Vesicular amine transporter (VAT) family members are integral proteins in the lipid bilayer of secretory vesicles in nerve and endocrine cells. They allow the transport of acetylcholine and biogenic amines to secretory vesicles to be released into the extracellular space through exocytosis [6-8]. Vesicle amine transport protein 1 (VAT1) was first described in 1989 as a $41 \mathrm{kDa}$ integral membrane protein that is a major component of synaptic vesicles and serves to transfer monoamines such as dopamine, norepinephrine, and epinephrine between the synaptic and cytosol vesicles $[9,10]$. The VAT1 gene is located on chromosome $17 \mathrm{q} 21$, in the proximity of the BRCA1 gene that is implicated in genetic susceptibility to ovarian and breast cancers [10-12]. In addition, the expression of VAT1 is upregulated in a variety of diseases, including benign prostatic hyperplasia [13], and glioblastomas [14], but its expression in HCC remains unclear.

Together, these findings suggest that VAT1 may be relevant to the development of tumors. Therefore, we hypothesized that VAT1 is a prognostic marker for carcinoma. In this study, we first performed a bioinformatics analysis of VAT1 in open databases and then determined the expression of VAT1 in human HCC samples using immunohistochemistry. Finally, the relationship between VAT1 expression, clinicopatholog- 
ical parameters, and the overall survival rate was evaluated. The obtained results indicate that VAT1 may be a valuable biomarker for the prognosis and treatment of HCC.

\section{Patients and methods}

Patients and tissue samples. A total of 330 HCC tissue specimens were collected from January 2010 to December 2016 at the Zhejiang Provincial People's Hospital. The age of patients ranged from 25 to 90 years (median age, 56.9 years). The survival time was calculated from the date of surgery to the last follow-up or death. Control samples were obtained from adjacent noncancerous tissues $(5 \mathrm{~cm}$ away from the border of the tumor) in 190 patients, including 120 cases of hepatic lesion tissues and 70 cases of normal liver tissues. All samples were included in a tissue microarray (TMA) constructed by the Shanghai Outdo Biotech Company (Shanghai, China). Information on tumor size, location, number of tumors, Edmondson grade, the presence of metastases was collected from medical records. All participants signed written informed consent, and approval for the study was obtained from the Ethics Committee of the Zhejiang Provincial People's Hospital.

Assessment of VAT1 expression in HCC using bioinformatics databases. The analysis of differential expression of VAT1 mRNA in HCC and normal tissue utilized several online microarray databases, including Oncomine (https:// www.oncomine.org/resource/main.html), Ualcan (http:// ualcan.path.uab.edu/analysis.html), and GEPIA (http:// gepia.cancer-pku.cn/index.html). The specific parameters searched in these databases included sample type, cancer stage, tumor histology, nodal metastasis, and tumor grade. The prognostic value of VAT1 expression was further analyzed using Ualcan, GEPIA, and Linkomic (http://www. linkedomics.org/admin.php) databases; median survival was used for survival analysis.

Immunohistochemistry and evaluation of VAT1 protein expression. The changes in VAT1 protein expression were studied using a tissue microarray (TMA) comprising 330 samples of human HCC and 190 samples of non-carcinomatous human liver tissue. Briefly, slides were baked at $68^{\circ} \mathrm{C}$ for $2 \mathrm{~h}$, followed by deparaffinization, dehydration in xylene, and rehydration. Subsequently, the sections were immersed in the EDTA antigen retrieval buffer and boiled at $120^{\circ} \mathrm{C}$ in a pressure cooker for $3 \mathrm{~min}$. Sections were then treated with $3 \% \mathrm{H}_{2} \mathrm{O}_{2}$ for 15 min to inhibit the activity of endogenous peroxidase and $1 \%$ bovine serum albumin to reduce nonspecific binding. Specimens were incubated with rabbit anti-VAT1 antibody (ab252999, Abcam, Cambridge, UK) diluted $1: 500$ at $4^{\circ} \mathrm{C}$ overnight, washed 3 times with PBS, incubated with biotin-labeled secondary antibody for $20 \mathrm{~min}$ at room temperature and horseradish peroxidase-conjugated antibody for another $20 \mathrm{~min}$. Finally, tissue sections were stained with $\mathrm{DAB}$, counterstained with hematoxylin, dehydrated, washed, and mounted.
Immunostaining was assessed and scored according to staining intensity by two independent observers blinded to the clinical and pathological data. In case of differences, a consensus score was selected. Staining intensity scores were assigned as follows: no staining $=0$, light yellow $=1$ (weak staining), yellowish-brown $=2$ (moderate staining), brown $=3$ (strong staining). The proportion of stained cells was scored as 0 for $<5 \%$ cells stained, 1 for $6-26 \%$ cells stained, 2 for $26-50 \%$ cells stained, and 3 for $\geq 50 \%$ cells stained. The staining index was calculated by multiplying the intensity and proportion scores. Staining index $\geq 4$ was considered to reflect a high expression of VAT1 and an index of less than 4 a low expression of VAT1.

Statistical analysis. The statistical analysis was performed using the Statistical Package for the Social Sciences (SPSS V.13.0 for Windows). The relationship between VAT1 expression and clinicopathological parameters was assessed with $\chi^{2}$ or Fisher's exact tests. The overall survival curve was generated by the Kaplan-Meier method, and the long-rank test was used to detect the difference between curves. To assess the prognostic value of VAT1 expression, multivariate survival analysis was performed using the Cox proportional hazard regression model. In all tests, p-values were two-tailed, and $\mathrm{p}<0.05$ was considered statistically significant.

\section{Results}

Analysis of VAT1 expression based on bioinformatics databases. To evaluate the expression of VAT1 mRNA, we searched Oncomine, GIAPIA, and Ualcan databases. Analysis of the Oncomine data has shown that the level of VAT1 mRNA was higher in HCC than in normal liver tissues in the Chen liver (Figure 1A), Wurmbach liver (Figure 1B), Roessler liver (Figure 1C), and Mas liver (Figure 1D) data sets. Similar results were obtained using the GEPIA (Figure 1E) and Ualcan (Figure 1F) databases. Further analysis of the Ualcan database documented that the median expression in normal samples $(\mathrm{n}=50)$ was 30.824 , and in primary tumor samples $(\mathrm{n}=371)$ was 63.228 , the median expression in of grade 1 tumors $(\mathrm{n}=54)$ was 49.666 , in grade $2(\mathrm{n}=173)$ was 54.588 , in grade $3(\mathrm{n}=118)$ was 84.914 , and in grade $4(\mathrm{n}=12)$ was 85.882 . In the absence of nodal metastases $(n=252)$, the median expression was 66.214, and in the presence of nodal metastases $(n=4)$ the median expression was 78.625. The median expression of VAT1 in grade 1 cancer $(\mathrm{n}=168)$ was 57.552 , in grade $2(\mathrm{n}=84)$ was 66.867 , in grade $3(\mathrm{n}=82)$ was 72.064 , and in grade $4(n=6)$ was 71.38 . When histological subtypes were considered, the median expression in hepatocellular carcinoma $(n=361)$ was 60.144 , in fibrolamellar carcinoma $(n=3)$ was 81.872 , and in mixed hepatocholangiocarcinoma $(n=7)$ was 71.787. Thus, the level of VAT1 mRNA in HCC tumors of any grade (Figure 1G), in the presence or absence of nodal metastasis (Figure 1H), in cancer of any stage (Figure 1I), and regardless of the histological subtype (Figure 1J) was significantly higher than in the normal liver tissue. 
A

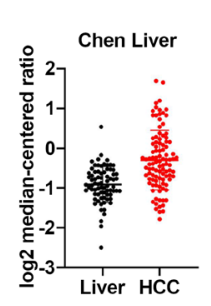

E

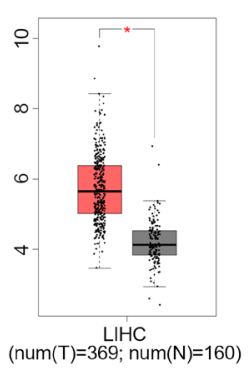

B

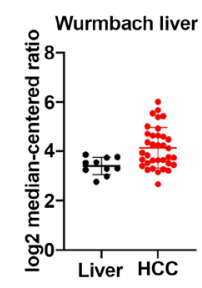

$F$

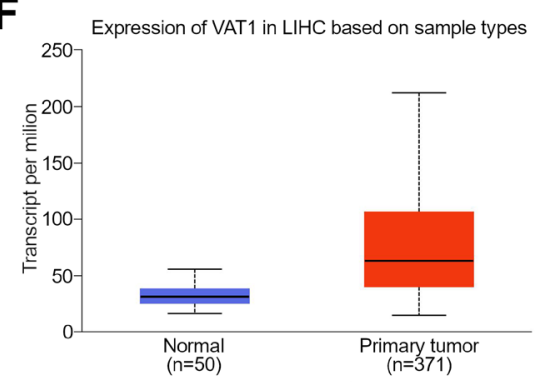

C Roessler Liver

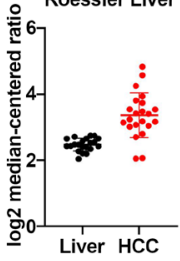

D

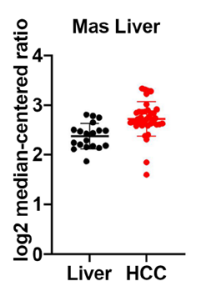

G
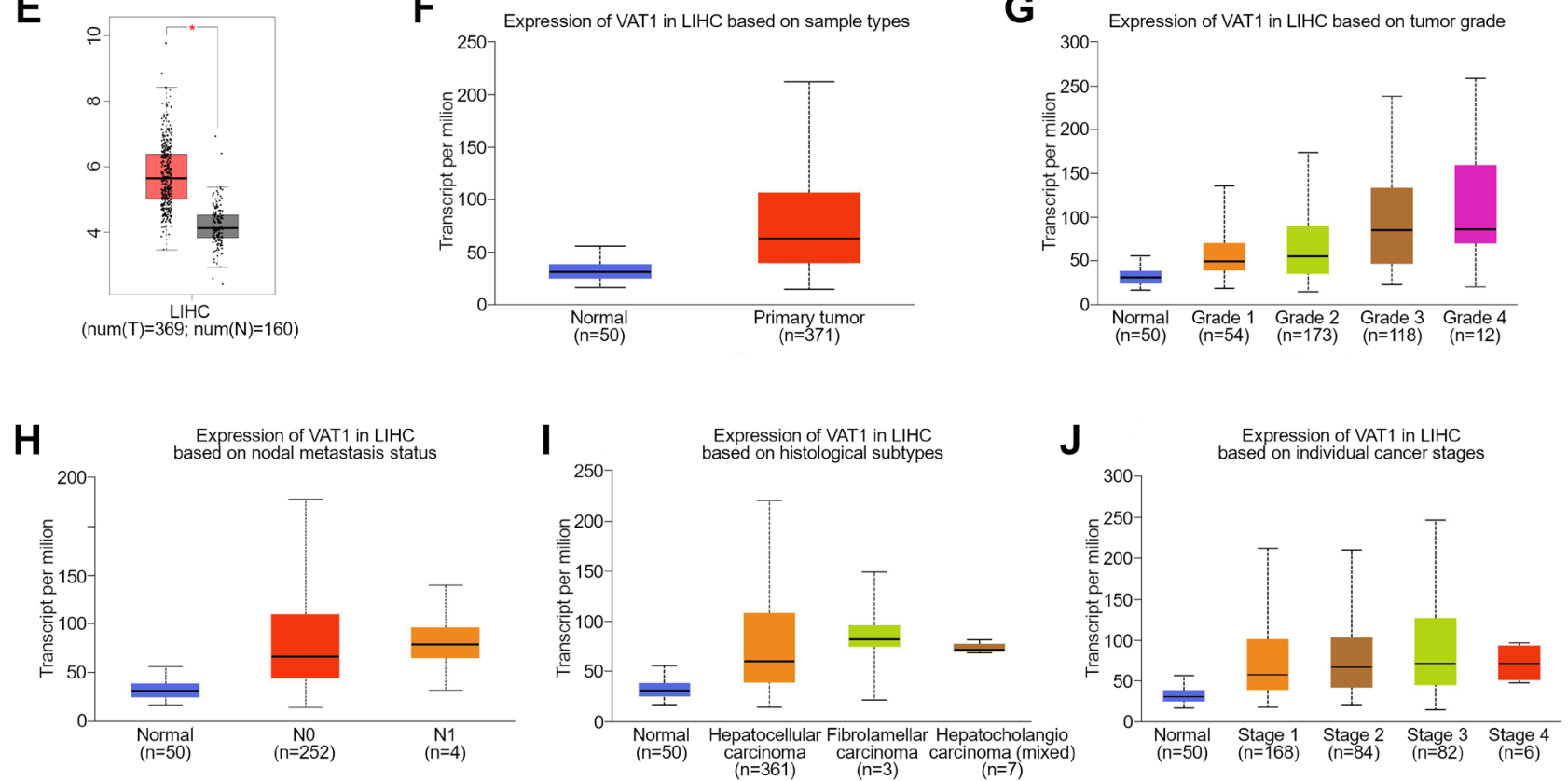

Figure 1. The correlation between VAT1 expression and prognosis of HCC based on bioinformatics analysis. A-E) Expression of VAT1 mRNA in HCC and liver tissues based on the Oncomine (A-D) and GIAPIA (E) databases. F-J) Expression of VAT1 mRNA according to sample types, tumor grade, metastasis status, cancer stage, and histological subtypes based on the Ualcan database.

A

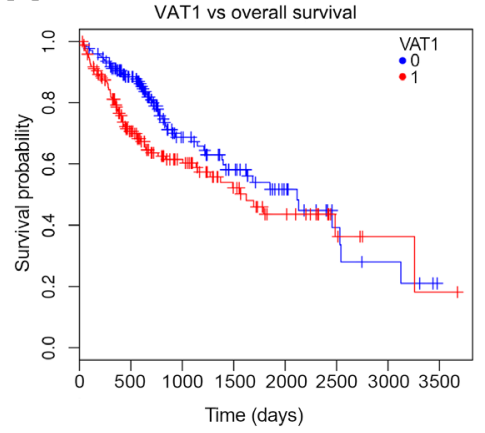

LINKOMIC database
B

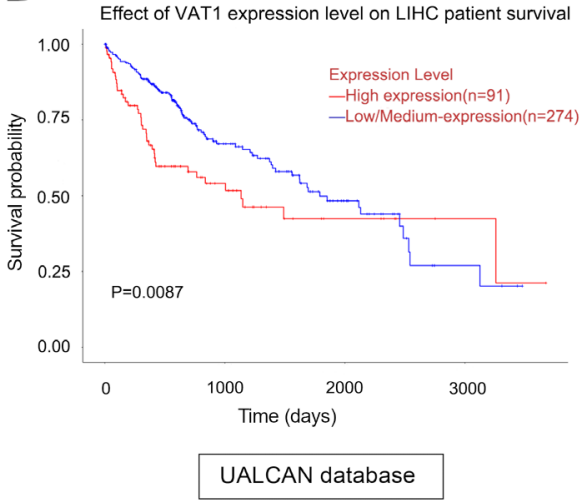

C

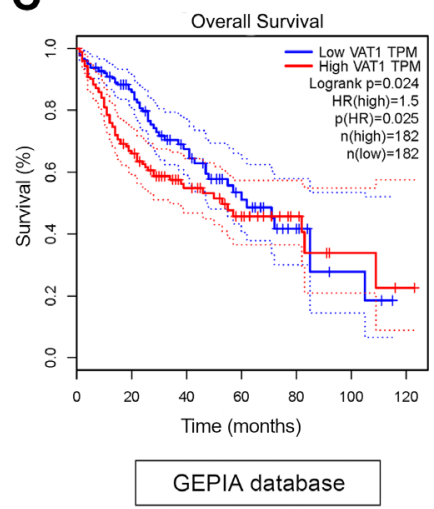

Figure 2. The prognostic value of VAT1 levels in HCC patients. A-C) Survival curves were plotted based on the Linkomic (A), Ualcan (B), and GEPIA (C) databases.

To evaluate the correlation between the expression of VAT1 and the prognosis of patients, the Linkomic, Ualcan, and GEPIA databases were used. The analysis of KaplanMeier curves from Linkomic (log-rank test, $\mathrm{p}<0.05$;
Figure 2A), Ualcan (log-rank test, $\mathrm{p}<0.05$; Figure $2 \mathrm{~B}$ ), and GEPIA (long-rank test, $\mathrm{p}<0.05$; Figure $2 \mathrm{C}$ ) documented that the high expression of VAT1 mRNA was significantly associated with poor clinical outcome. 
Overexpression of VAT1 in HCC tissues. The expression of VAT1 protein in the cytoplasm of HCC samples and non-tumor tissues was determined by immunohistochemistry. The results of immunostaining showed that no or very little expression of VAT1 in non-tumorous tissues, and intermediate and strong expression of VAT1 in HCC tissues (Figures 3A-3D). VAT1 protein was detected in 22 of 190 (11.6\%) human non-tumorous liver tissues, and in 237 of 330 (71.8\%) samples of HCC (Figure 4), indicating significant upregulation of expression in HCC tissues ( $<<0.01$, Table 1 ).

Correlation between the expression of VAT1 protein and clinicopathologic features of HCC. The results of the analysis of the correlation between VAT1 expression and clinicopathological parameters are presented in Table 2. Positive expression of VAT1 correlated with patient age, tumor size, number of tumors, and microvascular invasion $(\mathrm{p}<0.05)$, but did not correlate in a statistically significant manner with patient gender $(\mathrm{p}=0.269)$, presence of metastases $(\mathrm{p}=0.102)$, Edmonson grade $(\mathrm{p}=0.432)$, cirrhosis $(\mathrm{p}=0.795)$, and HBV infection ( $\mathrm{p}=0.776)$.

The significance of VAT1 expression for the prognosis of HCC. The median survival time of patients with low protein expression of VAT1 ( $47.575 \pm 2.807$ months) was significantly longer than that of patients with high expression of VAT1 (39.473 \pm 2.188 months, $\mathrm{p}<0.05)$. Additionally, Kaplan-Meier analysis showed that high expression of VAT1 was associated with shorter overall survival ( $\mathrm{p}<0.05$, Figure 5$)$.
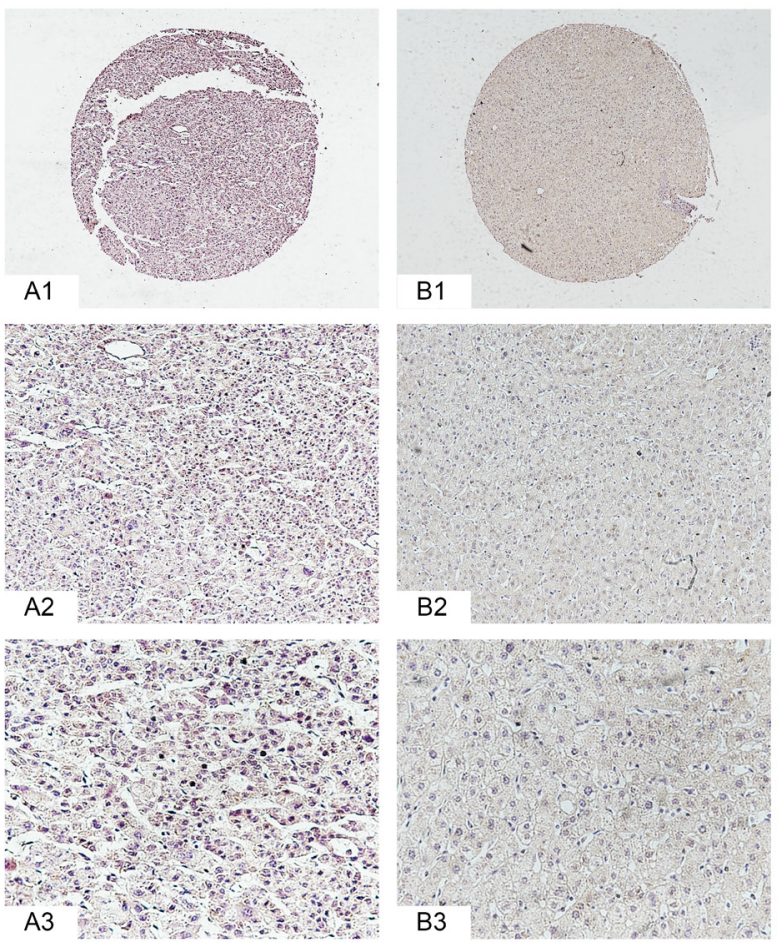
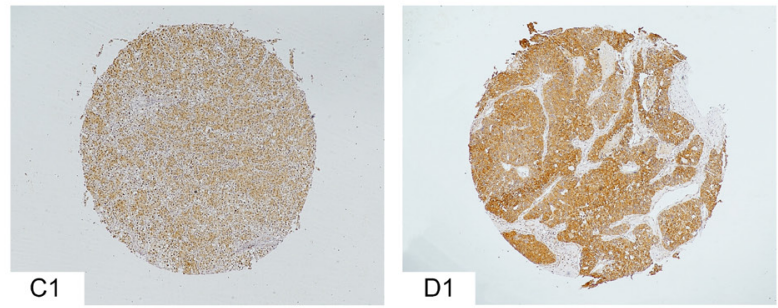

Table 1. Expression of VAT1 mRNA in HCC and non-carcinomatous liver tissues.

\begin{tabular}{lcccc}
\hline \multirow{2}{*}{ Samples } & \multicolumn{4}{c}{ VAT1 expression } \\
\cline { 2 - 5 } & Number & Negative & Positive & p-value \\
\hline HCC & 330 & 93 & 237 & $<0.01$ \\
Non-carcinomatous liver tissues & 190 & 168 & 22 & \\
\hline
\end{tabular}

Univariate analysis of the important factors affecting the survival was then performed and documented that the length of survival correlated with tumor size $(\mathrm{p}=0.01)$, Edmondson grade $(\mathrm{p}<0.01)$, metastasis $(\mathrm{p}<0.01)$, microvascular invasion $(p<0.01)$, and VAT1 expression $(p=0.04)$ (Table 3). These factors were entered into the Cox proportional hazard regression model, and the results demonstrated that metastasis and the Edmonson grade were independent factors affecting the prognosis of HCC patients, while tumor size, microvascular invasion, and VAT1 expression were not (Table 3).

\section{Discussion}

HCC is one of the most common malignancies of the digestive system. Although some progress has been made in the diagnosis and treatment, the five-year survival of HCC patients remains unsatisfactory. In recent years, AFP has been the most commonly used marker for early screening of HCC, but the effective detection rate is still only about 70 percent
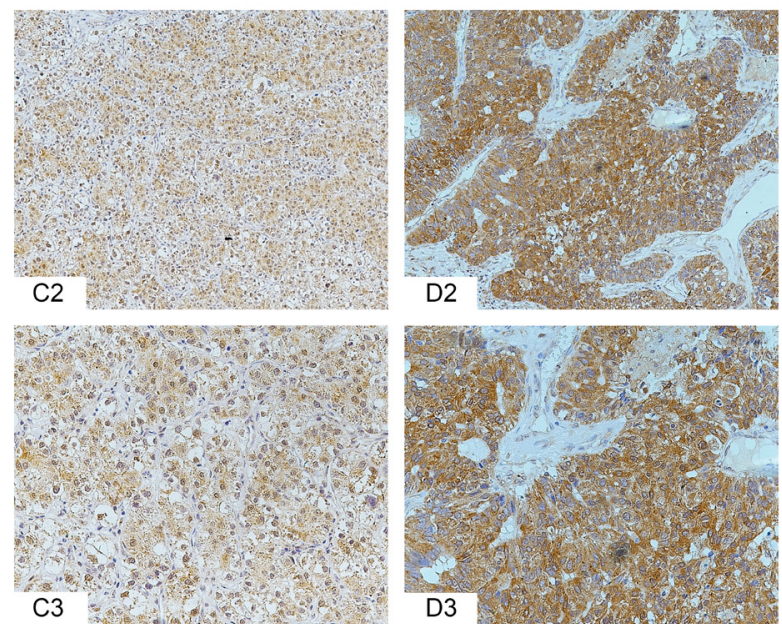

Figure 3. Immunohistochemical staining for VAT1 in HCC tissues and normal tissue adjacent to the tumor. A1-A3) Negative control of VAT1 in HCC (PBS was used instead of primary antibody). B1-B3) VAT1 showed low expression in normal tissue adjacent to the HCC. C1-C3) Moderate expression of VAT1 in HCC tissue. D1-D3) High expression of VAT1 in HCC tissue. Original magnification: A1-D1, ×40; A2-D2, ×200; A3-D3, ×400. 
Table 2. Relationship between VAT1 expression and clinicopathological parameters of HCC patients.

\begin{tabular}{|c|c|c|c|c|}
\hline \multirow{2}{*}{ Clinical parameters } & \multicolumn{4}{|c|}{ VAT1 expression } \\
\hline & Low & High & $\chi^{2}$ & p-value \\
\hline Gender & & & 1.221 & 0.269 \\
\hline Male & $72(77.4 \%)$ & $196(82.7 \%)$ & & \\
\hline Female & $21(22.6 \%)$ & $41(17.3 \%)$ & & \\
\hline Age (yrs) & & & 7.731 & 0.005 \\
\hline$<55$ & $25(26.9 \%)$ & $103(43.5 \%)$ & & \\
\hline$\geq 55$ & $68(73.1 \%)$ & $134(56.5 \%)$ & & \\
\hline Size & & & 6.837 & 0.009 \\
\hline$<5 \mathrm{~cm}$ & $60(64.5 \%)$ & $111(48.5 \%)$ & & \\
\hline$\geq 5 \mathrm{~cm}$ & $33(35.5 \%)$ & $118(51.5 \%)$ & & \\
\hline Number of tumors & & & 6.296 & 0.012 \\
\hline single & $84(90.3 \%)$ & $186(78.5 \%)$ & & \\
\hline multiple & $9(9.7 \%)$ & $51(21.5 \%)$ & & \\
\hline Metastasis & & & 2.672 & 0.102 \\
\hline M0 & $88(95.7 \%)$ & $209(90.1 \%)$ & & \\
\hline M1 & $4(4.3 \%)$ & $23(9.9 \%)$ & & \\
\hline Microvascular invasion & & & 9.371 & 0.002 \\
\hline No & $49(65.3 \%)$ & $75(44.1 \%)$ & & \\
\hline Yes & $26(34.7 \%)$ & $95(55.9 \%)$ & & \\
\hline Edmondson grade & & & 0.618 & 0.432 \\
\hline $\mathrm{I}+\mathrm{II}$ & $60(66.7 \%)$ & $145(62.0 \%)$ & & \\
\hline III & $30(33.3 \%)$ & $89(38.0 \%)$ & & \\
\hline Cirrhosis & & & 0.067 & 0.795 \\
\hline negative & $32(34.4 \%)$ & $78(32.9 \%)$ & & \\
\hline positive & $61(65.6 \%)$ & $159(67.1 \%)$ & & \\
\hline $\mathrm{HBV}$ & & & 0.081 & 0.776 \\
\hline Absent & $9(20.4 \%)$ & $44(19.0 \%)$ & & \\
\hline Present & $74(79.6 \%)$ & $187(81.0 \%)$ & & \\
\hline
\end{tabular}

The total number of cases is less than 330 because of incomplete pathological data.
HCC
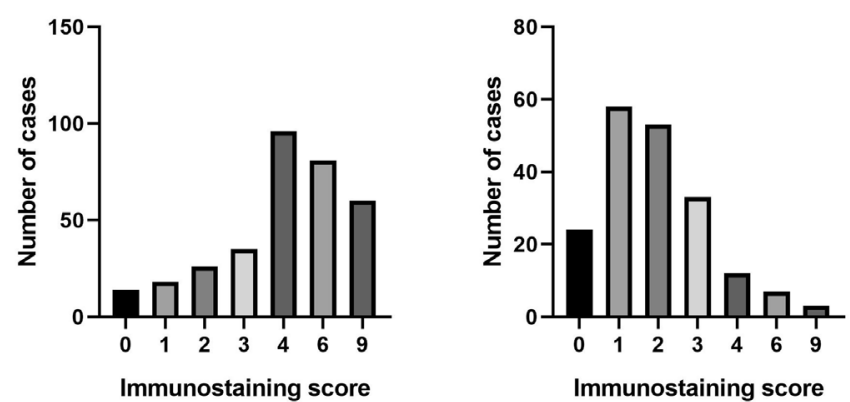

Figure 4. The distribution of immunohistochemical scores of hepatocellular carcinoma and non-carcinomatous liver tissues.

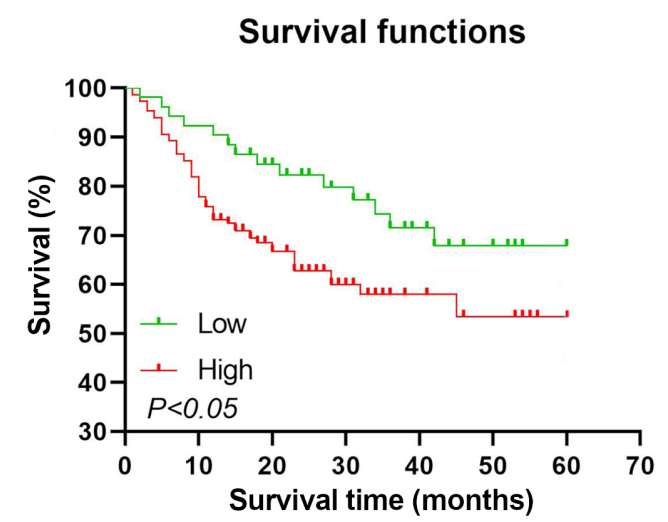

Figure 5. Kaplan-Meier survival curves showed that HCC patients with high expression of VAT1 have a poorer prognosis than those with low expression of VAT $1(\mathrm{p}<0.05)$.

Table 3. Univariate and multivariate Cox regression survival analysis of clinicopathological parameters and VAT1 expression in hepatocellular carcinoma patients.

\begin{tabular}{|c|c|c|c|c|c|c|}
\hline \multirow{2}{*}{ Parameters } & \multicolumn{3}{|c|}{ Univariate analysis } & \multicolumn{3}{|c|}{ Multivariate analysis } \\
\hline & HR & $95 \%$ CI & p-value & HR & $95 \%$ CI & p-value \\
\hline Age & 0.66 & $0.41-1.05$ & 0.08 & & NA & \\
\hline Gender & 1.55 & $0.91-2.64$ & 0.11 & & NA & \\
\hline Tumor size & 1.96 & $1.22-3.31$ & 0.01 & 1.16 & $0.56-2.41$ & 0.68 \\
\hline Number of tumors & 1.25 & $0.69-2.29$ & 0.46 & & NA & \\
\hline Edmondson grade & 2.75 & $1.72-4.41$ & $<0.01$ & 2.55 & $1.20-5.41$ & 0.02 \\
\hline Metastasis & 4.83 & $2.56-9.14$ & $<0.01$ & 3.76 & $1.42-9.96$ & 0.01 \\
\hline Microvascular invasion & 2.16 & $1.28-3.66$ & $<0.01$ & 1.15 & $0.55-2.41$ & 0.71 \\
\hline HBs antigen & 1.16 & $0.65-2.09$ & 0.61 & & NA & \\
\hline Cirrhosis & 1.14 & $0.69-1.89$ & 0.60 & & NA & \\
\hline AFP level & 2.49 & $1.39-4.49$ & $<0.01$ & 1.87 & $0.90-3.91$ & 0.10 \\
\hline VAT1 expression & 1.86 & $1.04-3.32$ & 0.04 & 2.33 & $0.97-5.63$ & 0.06 \\
\hline
\end{tabular}

Abbreviations: HBs antigen - hepatitis B surface antigen; AFP - alpha-fetoprotein; HR - hazard ratio; CI - confidence interval

[15]. Therefore, the search for effective tumor markers is one of the focal points of current HCC research.

VAT family of proteins is essential for intracellular transport, cell survival, and cell homeostasis. Previous studies have shown that in the VAT gene knockout animals, the levels of dopamine, norepinephrine, and serotonin in the brain drop sharply [16-18]. VAT1 is an integral membrane protein embedded in synaptic vesicles. Besides the involve- 
ment in intracellular transport, which is typical of the entire VAT family, VAT1 is related to ATPase activity [19]. Multiple studies have investigated the role of VAT1 in different diseases $[12,13]$. Using the GEPIA and Ualcan databases, we demonstrated that the expression of VAT1 in HCC was higher than in normal liver tissue. Next, we focused on the relationship between VAT1 and tumor progression, clinicopathological characteristics, and overall survival. By immunohistochemistry, we have detected the expression of VAT1 in 330 HCC samples and 190 normal liver samples. The analysis of the association between immunohistochemical score and clinicopathological and genetic features shown that VAT1 is not only highly expressed in HCC, but it also correlates with age $(\mathrm{p}<0.05)$, tumor size $(\mathrm{p}<0.05)$, number of tumors $(\mathrm{p}<0.05)$, and microvascular invasion $(\mathrm{p}<0.05)$. These findings raise the possibility that VAT1 could promote tumor development and dissemination. Additionally, to evaluate the prognostic value of VAT1 in HCC, we applied Kaplan-Meier analysis to data available from public resources and found that the mean survival time of patients with high VAT1 expression was significantly shorter than that of patients with low expression. This result implies that the expression of VAT1 can be used as an effective indicator to identify the high-risk population and predict the prognosis of HCC patients.

To summarize, by combining the public database information on tumor gene expression with determinations in clinical samples, we advanced the understanding of the mechanism of action of molecular oncogenes in HCC. This study demonstrated that VAT1 plays an important role in HCC and that VAT1 overexpression is associated with the overall survival of HCC patients, suggesting the predictive value of high VAT1 expression for poor prognosis. Additionally, the knowledge of the expression of VAT1 in HCC will help identify patients with high metastatic potential. In conclusion, VAT1 may play an essential role in the progression of HCC, and the level of its expression may be an effective predictor of the invasion and prognosis of HCC.

Some limitations of this study should be acknowledged. During the analysis, it appeared that the number of certain samples in public databases is insufficient and may not be representative of the entire population of HCC patients. Additional limitations include the subjective nature of scoring based on immunohistochemistry score and the limited number of clinical samples. However, we are confident that the sample size in the database and the number of clinical cases will continue to expand with time, allowing us to strengthen the conclusions of the present work.

Acknowledgments: This study was funded by the Natural Science Foundation of Zhejiang Province (grant number GF19H160084) and Zhejiang Chinese Medicine Administration (grant number 2017ZZ002).

\section{References}

[1] BRAY F, FERLAY J, SOERJOMATARAM I, SIEGEL RL, TORRE LA et al. Global cancer statistics 2018: GLOBOCAN estimates of incidence and mortality worldwide for 36 cancers in 185 countries. CA Cancer J Clin 2018; 68: 394-424. https://doi.org/10.3322/caac.21492

[2] GLOBAL BURDEN OF DISEASE LIVER CANCER COLLABORATION, AKINYEMIJU T, ABERA S, AHMED M, ALAM N et al. The Burden of Primary Liver Cancer and Underlying Etiologies From 1990 to 2015 at the Global, Regional, and National Level: Results From the Global Burden of Disease Study 2015. JAMA Oncol 2017; 3: 1683-1691. https://doi.org/10.1001/jamaoncol.2017.3055

[3] TOKUMITSU Y, SAKAMOTO K, TOKUHISA Y, MATSUI $\mathrm{H}, \mathrm{MATSUKUMA} S$ et al. A new prognostic model for hepatocellular carcinoma recurrence after curative hepatectomy. Oncol Lett 2018; 15: 4411-4422. https://doi.org/10.3892/ ol.2018.7821

[4] ZHU Q, LI N, ZENG X, HAN Q, LI F et al. Hepatocellular carcinoma in a large medical center of China over a 10 -year period: evolving therapeutic option and improving survival. Oncotarget 2015; 6: 4440-4450. https://doi.org/10.18632/ oncotarget.2913

[5] ROMANO A, ANGELI P, PIOVESAN S, NOVENTA F, ANASTASSOPOULOS G et al. Newly diagnosed Hepatocellular Carcinoma in patients with advanced hepatitis $\mathrm{C}$ treated with DAAs: a prospective population study. J Hepatol 2018; 69: 345-352. https://doi.org/10.1016/j.jhep.2018.03.009

[6] EIDEN LE, SCHÄFER MKH, WEIHE E, SCHÜTZ B. The vesicular amine transporter family (SLC18): amine/proton antiporters required for vesicular accumulation and regulated exocytotic secretion of monoamines and acetylcholine. Pflugers Arch 2004; 447: 636-640. https://doi.org/10.1007/ s00424-003-1100-5

[7] PARSONS SM. Transport mechanisms in acetylcholine and monoamine storage. FASEB J 2000; 14: 2423-2434. https:// doi.org/10.1096/fi.00-0203rev

[8] WEIHE E, EIDEN LE. Chemical neuroanatomy of the vesicular amine transporters. Faseb Journal 2000; 14: 2435-2449. https://doi.org/10.1096/fj.00-0202rev

[9] LINIAL M, MILLER K, SCHELLER RH. VAT-1: an abundant membrane protein from Torpedo cholinergic synaptic vesicles. Neuron 1989; 2: 1265-1273. https://doi. org/10.1016/0896-6273(89)90311-5

[10] LINIAL M, LEVIUS O. VAT-1 from Torpedo is a membranous homologue of zeta crystallin. FEBS Lett 1993; 315: 9194. https://doi.org/10.1016/0014-5793(93)81140-u

[11] SMITH TM, LEE MK, SZABO CI, JEROME N, MCEUEN $\mathrm{M}$ et al. Complete genomic sequence and analysis of $117 \mathrm{~kb}$ of human DNA containing the gene BRCA1. Genome Res 1996; 6: 1029-1049. https://doi.org/10.1101/gr.6.11.1029

[12] SHAN X, WANG K, TONG X, WANG Z, WU F et al. High expression of VAT1 is a prognostic biomarker and predicts malignancy in glioblastoma. Oncol Rep 2019. https://doi. org/10.3892/or.2019.7276 
[13] MORI F, TANIGAWA K, ENDO K, MINAMIGUCHI K, $\mathrm{ABE} M$ et al. VAT-1 is a novel pathogenic factor of progressive benign prostatic hyperplasia. Prostate 2011; 71: 15791586. https://doi.org/10.1002/pros.21374

[14] MERTSCH S, BECKER M, LICHOTA A, PAULUS W, SENNER V. Vesicle amine transport protein-1 (VAT-1) is upregulated in glioblastomas and promotes migration. Neuropathol Appl Neurobiol 2009; 35: 342-352. https://doi. org/10.1111/j.1365-2990.2009.00993.x

[15] GUAN L, LUO Q, LIANG N, LIU H. A prognostic prediction system for hepatocellular carcinoma based on gene coexpression network. Exp Ther Med 2019; 17: 4506-4516. https://doi.org/10.3892/etm.2019.7494

[16] FON EA, POTHOS EN, SUN BC, KILLEEN N, SULZER $\mathrm{D}$ et al. Vesicular transport regulates monoamine storage and release but is not essential for amphetamine action. Neuron 1997; 19: 1271-1283. https://doi.org/10.1016/s08966273(00)80418-3
[17] TAKAHASHI N, MINER LL, SORA I, UJIKE H, REVAY RS et al. VMAT2 knockout mice: Heterozygotes display reduced amphetamine-conditioned reward, enhanced amphetamine locomotion, and enhanced MPTPtoxicity. Proc Natl Acad Sci U S A 1997; 94: 9938-9943. https://doi.org/10.1073/ pnas.94.18.9938

[18] WANG YM, GAINETDINOV RR, FUMAGALLI F, XU F, JONES SR et al. Knockout of the vesicular monoamine transporter 2 gene results in neonatal death and supersensitivity to cocaine and amphetamine. Neuron 1997; 19: 1285-1296. https://doi.org/10.1016/s0896-6273(00)80419-5

[19] HAYESS K, KRAFT R, SACHSINGER J, JANKE J, BECKMANN G. Mammalian protein homologous to VAT-1 of Torpedo californica: isolation from Ehrlich ascites tumor cells, biochemical characterization, and organization of its gene. J Cell Biochem 1998; 69: 304-315. 